\title{
Wirtschaftliche und Kommerzielle Entwicklungszusammenarbeit
}

La Coopération de la Suisse au développement:

Mesures économiques et commerciales

\section{Antoine Brawand}

\section{OpenEdition}

\section{Journals}

Édition électronique

URL : http://journals.openedition.org/sjep/971

DOI : $10.4000 /$ sjep.971

ISSN : 1663-9677

Éditeur

Institut de hautes études internationales et du développement

Édition imprimée

Date de publication : 31 août 1982

Pagination : 207-266

ISSN : 1660-5926

Référence électronique

Antoine Brawand, «Wirtschaftliche und Kommerzielle Entwicklungszusammenarbeit »,

Schweizerisches Jahrbuch für Entwicklungspolitik [En ligne], 2 I 1982, mis en ligne le 28 janvier 2013,

consulté le 08 septembre 2020. URL : http://journals.openedition.org/sjep/971 ; DOI : https://doi.org/ 10.4000/sjep.971

Ce document a été généré automatiquement le 8 septembre 2020

(c) The Graduate Institute 


\title{
Wirtschaftliche und Kommerzielle Entwicklungszusammenarbeit
}

\author{
La Coopération de la Suisse au développement: \\ Mesures économiques et commerciales
}

Antoine Brawand

\section{NOTE DE L'ÉDITEUR}

Zusammenfassung auf Deutsch. Volltext auf Französisch in Annuaire suisse de politique de développement: „La Coopération de la Suisse au développement : Mesures économiques et commerciales", http://aspd.revues.org/1136.

\section{RÉSUMÉS}

Der Verfasser vertritt den Standpunkt, dass die wirtschaftlichen Beziehungen zwischen der Schweiz und der dritten Welt durch ein schwerwiegendes Missverhältnis gekennzeichnet sind. Der Autor zeigt zunächst den wirtschaftlichen Kontext auf und befasst sich dann mit der Einbeziehung der Ziele der Entwicklungszusammenarbeit in das Feld der Wirtschaftspolitik. Seit dem 28. November 1978 gibt es einen Bundesbeschluss, der finanzielle Mittel für wirtschafts- und handelspolitische Massnahmen im Rahmen der internationalen Entwicklungszusammenarbeit freigibt. Von den Ausgaben her gesehen sind hauptsächlich die Mischkredite und die Zahlungsbilanzhilfe in diesen Massnahmen enthalten. Der Verfasser erörtert auch die Fragen der Grundprodukte, der Industrialisierung und der Handelsförderung zugunsten der Entwicklungsländer. Er analysiert die gegenwärtigen Handlungsprinzipien der Eidgenossenschaft 
im Bereich der Mischkredite, die Darlehensbedingungen, das Nutzungsfeld dieser Kredite und die Wahl der verschiedenen Länder als Empfänger einer solchen Hilfe. Es ist festzustellen, dass die Erteilung der Mischkredite den schweizerischen Aussenhandel dank Finanzierung der Lieferungen unterstützt. Dadurch festigt sich auch die Stellung schweizerischer Firmen auf manchen Handelsplätzen. Zum Abschluss dieser Untersuchung kommt der Verfasser zu dem Ergebnis, dass die Aussenwirtschaftspolitik noch $\mathrm{zu}$ wenig die Zielen der Entwicklungszusammenarbeit berücksichtigt. Es geht vor allem darum, die Tätigkeit der Privatunternehmen effektiv in eine für die Entwicklung günstige Richtung zu steuern.

\section{AUTEUR}

\section{ANTOINE BRAWAND}

Chargé de cours à l'Institut universitaire d'études du développement, Genève 